\title{
Heteroepitaxial $\mathrm{ZnO}$ nano hexagons on p-type $\mathrm{SiC}$
}

\author{
Volodymyr Khranovskyy, I Tsiaoussis, Gholamreza Yazdi, Lars Hultman and Rositsa \\ Yakimova
}

\section{Linköping University Post Print}

N.B.: When citing this work, cite the original article.

Original Publication:

Volodymyr Khranovskyy, I Tsiaoussis, Gholamreza Yazdi, Lars Hultman and Rositsa Yakimova, Heteroepitaxial $\mathrm{ZnO}$ nano hexagons on p-type SiC, 2010, JOURNAL OF CRYSTAL GROWTH, (312), 2, 327-332.

http://dx.doi.org/10.1016/j.jcrysgro.2009.09.057

Copyright: Elsevier http://www.elsevier.com/

Postprint available at: Linköping University Electronic Press

http://urn.kb.se/resolve?urn=urn:nbn:se:liu:diva-54065 


\title{
Heteroepitaxial $\mathrm{ZnO}$ nano hexagons on p-type $\mathrm{SiC}$
}

\author{
V Khranovskyy ${ }^{1}$, I Tsiaoussis ${ }^{2}$, G R Yazdi ${ }^{1}$, L Hultman $^{1}$ and R Yakimova ${ }^{1}$ \\ 1 Department of Physics, Chemistry and Biology (IFM), Linköping University, SE-58183 \\ Linköping, Sweden \\ ${ }^{2}$ Solid State Physics Section, Department of Physics, Aristotle University of Thessaloniki, GR- \\ 54124 Thessaloniki, Greece
}

\begin{abstract}
$\mathrm{ZnO}$ single crystal nanohexagons have been grown heteroepitaxially on p-type $\mathrm{Si}$-face $4 \mathrm{H}-\mathrm{SiC}$ substrates with $8^{\circ}$ miscut from [0001] by catalyst-free atmospheric pressure metalorganic chemical vapor deposition and characterized by x-ray diffraction, scanning and transmission electron microscopy as well as energy disperse x-ray and cathodoluminescence analyses. The as-grown $\mathrm{ZnO}$ nanohexagons have a pillar shape terminated by $a$ and $c$ plane facets, and are aligned along the growth direction with the epitaxial relation $[0001]_{\mathrm{ZnO}} / /[0001]_{4 \mathrm{H}-\mathrm{SiC}}$ and $\left[\begin{array}{lll}10 & \overline{1} & 0\end{array}\right]_{\mathrm{ZnO}} / /\left[\begin{array}{lll}10 & \overline{1} & 0\end{array}\right]_{4 \mathrm{H}-\mathrm{Sic}}$. The $\mathrm{ZnO}$ nanohexagons demonstrate intense $\mathrm{UV}$ emission $\left(\lambda_{\mathrm{NBE}}=376 \mathrm{~nm}\right)$ and negligible defect related luminescence.
\end{abstract}

PACS: 81.16.-c, 81.07.-b, 61.46.Km, 68.37.Lp, 78.67.-n

Keywords: A1. Crystal structure, A1. Nanostructures, A1. Interfaces, A3. Metalorganic chemical vapor deposition, B3. Light emitting diodes.

*Corresponding author: Volodymyr Khranovskyy, Linkoping University, Department of Physics, Chemistry and Biology, SE-58183, Linkoping, Sweden Tel.: +4613285776 Fax : +4613142337 E-mail: volkh@ifm.liu.se 


\section{Introduction}

During the last decade $\mathrm{ZnO}$ has become interesting as a semiconductor material for device fabrication. Due to its properties such as wide band gap (3.37 eV at RT), high exciton binding energy (60 meV at RT), and optical transparency for visible light, $\mathrm{ZnO}$ is a prospective material for micro-, opto- and transparent electronics [1]. Implementations in room temperature spintronics are also foreseen [1]. Recently promising application of $\mathrm{ZnO}$ as UV nanolasers [2], field effect transistors [3], solar cell electrodes [4] and nanogenerators [5] have been reported. $\mathrm{ZnO}$ exhibits aptitude for nanotechnology, due to its viability to be grown as low-dimensional nanoscaled structures of various shapes and morphologies. Indeed, $\mathrm{ZnO}$ possesses the richest family of nanostructures being obtained [6]. Additional advantages are the convenience and simplicity of the growth techniques, in comparison to other wide band gap semiconductors, e.g. $\mathrm{GaN}$ and $\mathrm{SiC}$.

However, it remains a central issue to obtain spectrally monochromatic $\mathrm{ZnO}$ material. Having a band gap of $3.37 \mathrm{eV}, \mathrm{ZnO}$ should emit in the range of $366 \mathrm{~nm}$ to $380 \mathrm{~nm}$ (A-UV radiation), but commonly the emission spectra of $\mathrm{ZnO}$ consist of two luminescence bands. The narrow peak of the near band edge excitonic emission is typically accompanied by a broad visible emission, so called "green-yellow" luminescence, centered at $\lambda=550 \mathrm{~nm}[7,8]$. The origin of the visible luminescence is still under debate, but it is most probably related to $\mathrm{Zn}$ atoms as interstitials $\left(\mathrm{Zn}_{\mathrm{i}}\right)$ and/or oxygen vacancies $\left(\mathrm{V}_{\mathrm{o}}\right)$ [9]. Recently, we demonstrated that hydrogen incorporation into $\mathrm{ZnO}$ nanostructured films results in a "purification" of the $\mathrm{ZnO}$ emission spectra and an increase of the near band edge (NBE) excitonic emission intensity [10]. Another persistent problem is to obtain p-type material: usually the intrinsic (as-grown) $\mathrm{ZnO}$ is of n-type conductivity, which is difficult to overcome due to a self-compensation effect. 
Nevertheless, there are several reports claiming a successful p-type ZnO preparation, e. g., [1115]. However, the low hole mobility [12], time instability [13], non-reproducibility [14] and/or impractical growth techniques [15] of the obtained material brings doubts whether the p-type problem is as by today confidently solved. While light-emitting diodes based on $\mathrm{ZnO} \mathrm{p}$ - $\mathrm{n}$ homojunction have been reported [16], the prepared devices demonstrated low optical quality with defect-related luminescence in the visible range [17] and low emission intensity [18].

An alternative approach may be the heteroepitaxial growth of $\mathrm{ZnO}$ on p-type $\mathrm{SiC}$ [19]. SiC is attractive due to the similarity of the crystal structures and small lattice and thermal mismatch $a_{6 \mathrm{H}-\mathrm{SiC}}=0.308 \mathrm{~nm}, \mathrm{TEC}_{6 \mathrm{H}-\mathrm{SiC}}=4.3 \times 10^{-6} / \mathrm{K}$, while $a_{\mathrm{ZnO}}=0.3252 \mathrm{~nm}, \mathrm{TEC}_{\mathrm{ZnO}}=6.51 \times 10^{-6} / \mathrm{K}[20$, 21], giving a misfit in the basal plane 5.4\%. Although a high interest in fabrications of $\mathrm{ZnO} / \mathrm{p}$ SiC heterojunctions has been shown in recent years, efficient UV light emitting diodes have not been proven [9]. Structural/interfacial defects are suggested to be responsible for the enhancement of the defect emission and the quenching of NBE emission [10]. Since Park and Yi demonstrated potential applications of $\mathrm{ZnO}$ nanorods for ultraviolet light emitting diodes [22], heterostructures of $\mathrm{ZnO}$ nanorods on different substrates have been intensively studied. This far the nanorods have been considered non-faceted. Decreasing the size of the $\mathrm{ZnO}$ functional elements (nanosized p-n junction) can be a solution toward obtaining monoemission spectra due to a better structural quality and improved stoichiometry, which is a common problem in II-VI compounds. The quality of the hetero interface is of primary importance, since it may be an origin of extended defects acting as non-radiative recombination centers [23]. The influence of heterointerface roughness on $\mathrm{ZnO}$ nanorods growth has been investigated by Park et al. [24]. Atomically abrupt heterojunction of $\mathrm{ZnO}$ nanorods on $\mathrm{SiC}$ nanowires was recently reported [25]. However, both materials had a developed random morphology, which limits their applications. Hence, the fabrication of aligned nanosize $\mathrm{ZnO} / \mathrm{SiC}$ heterojunctions of high structural and 
interface quality, capable of monochromatic intense light emission remains a significant nanotechnological challenge.

In this paper we report epitaxial growth of self-aligned n-type $\mathrm{ZnO}$ hexagonal nanorods (nanohexagons) on p-type 4H-SiC substrates. We demonstrate enhanced UV emission in this asprepared $\mathrm{ZnO}$ material, consistent with the accomplished improvements in structure and interface quality.

\section{Experimental details}

\subsection{Sample growth}

The $\mathrm{ZnO}$ nanostructures were grown by atmospheric pressure metalorganic chemical vapor deposition (APMOCVD) using $\mathrm{Zn}$ acetylacetonate and oxygen as zinc and oxygen precursors, respectively. The substrate temperature was kept at $500{ }^{\circ} \mathrm{C}$, the flow rates of $\mathrm{Ar}$, as a buffer gas, and oxygen were 50 and $25 \mathrm{sccm}$, respectively [26]. The commercial 4H-SiC [0001] substrates were miscut by $8^{\circ}$ off the c- axis to [11 20 ] and then a p-SiC layer was grown by sublimation epitaxy [27]. The layer thickness and the net acceptor concentrations were $\sim 30 \mu \mathrm{m}$

and $\sim 5 \times 10^{16} \mathrm{~cm}^{-3}$, respectively. The off-axis substrate provides conditions for step flow growth mode of SiC, which typically results in step bunching yielding terraces with different width [28]. We supposed that the steps on such surfaces would favor the nucleation process.

\subsection{Characterization}

Structural properties of the $\mathrm{ZnO}$ samples were investigated by $\mathrm{x}$-ray diffraction (XRD) via $\theta-2 \theta$ scans and pole figures using a Siemens D5000 difractometer, utilizing $\mathrm{Cu}-\mathrm{K} \alpha$ radiation $(\lambda=0.1542 \mathrm{~nm})$. Scanning electron microscopy $(\mathrm{SEM})$ was used to characterize microstructure and elemental mapping was made by Energy Disperse X-ray (EDX) analysis in a Leo 1550 Gemini SEM (at operating voltage ranging from $10 \mathrm{kV}$ to $20 \mathrm{kV}$ and standard aperture value 30 $\mu \mathrm{m})$. The microstructure study of the $\mathrm{ZnO}$ nanorods was carried out using conventional and 
high-resolution TEM (HRTEM). For the cross-section TEM (XTEM) specimen preparation, two strips of the specimen were cut and glued face to face, then were mechanically thinned down to $25 \mu \mathrm{m}$. Subsequently the specimens were thinned to electron transparency by Ar ion milling with energy of $4 \mathrm{kV}$, at a low incident angle of $4^{\circ}$ in order to avoid amorphisation artefacts from the argon ions. For the conventional characterization a TEM JEM $120 \mathrm{CX}$ was used, while for the HRTEM investigation a JEM 2011 having $0.194 \mathrm{~nm}$ point to point resolution was utilized. Cathodoluminescence (CL) spectra were taken in the Leo 1550 Gemini SEM equipped with a MonoCL system (Oxford Instruments) using a $10 \mathrm{keV}$ electron beam and $30 \mu \mathrm{m}$ of aperture with 1800 lines $\mathrm{mm}^{-1}$ grating. Panchromatic images of $\mathrm{ZnO} / \mathrm{SiC}$ samples were taken to trace the difference in emission intensity.

\section{Results and discussion}

Figure 1(a) and 1(b) present SEM images taken from an as-grown sample. The sample exhibits surface steps along $\mathrm{SiC}$ [11-20] and nano hexagons. Due to anisotropy of growth rate in wurtzite semiconductors and minimization of the surface energy, vicinal surfaces of SiC show self-ordering phenomena, resulting in step bunching [29]. In our $8^{\circ}$ off $4 \mathrm{H}-\mathrm{SiC}$ the bunched step configurations with an integer number $(1,2,3, \ldots)$ of unit cell height are energetically stabilized where the number depends on the growth conditions [30]. Here, the $4 \mathrm{H}-\mathrm{SiC}$ utilized has $20 \mathrm{~nm}$ bunched step height. The nanohexagons of alleged $\mathrm{ZnO}$ composition in figure 1(a) and (b) have an $a$-plane-faceted hexagonal shape (1 $\overline{2} 00)$ facets with a top c-plane facet reflecting the crystal symmetry of $\mathrm{ZnO}$ and suggesting a single-crystal nature. These hexagons have a characteristic azimuthal diameter of $200-350 \mathrm{~nm}$ and height of $\sim 200 \mathrm{~nm}$. Figure 1(c) is a sketch illustrating the orientation relationship between the $\mathrm{ZnO}$ nanohexagons and the $\mathrm{SiC}$ substrate. The nanohexagons are aligned along the $\mathrm{ZnO}$ c-axis with an $8^{\circ}$ tilt corresponding to the substrate miscut. It should be mentioned that during the XRD measurements it was possible to identify the 
signal from $\mathrm{ZnO} \mathrm{HEX}$ only after subtraction of $8^{\circ}$ from the angle of the incident $\mathrm{x}$-ray beam, assuming $8^{\circ}$ misorientation from the c-axis towards [1120] direction. This is actually the step flow direction during the growth of the $\mathrm{SiC}$ epitaxial layer. This shows that the $\mathrm{ZnO}$ nanohexagons were grown not perpendicularly to the substrate plane, but to the (0001) plane of $\mathrm{SiC}$, i.e., epitaxially onto the $\mathrm{SiC}$ substrate. Figure 2 shows cross-sectional TEM micrographs from the $\mathrm{ZnO} / \mathrm{SiC}$ heterointerface taken along the $4 \mathrm{H}-\mathrm{SiC}\left[11 \overline{2}^{-} 0\right]$ zone axis (along the step edges as an overview and a higher magnification image. While a few crystallites touch each other, as seen in SEM (Figure. 1a), the apparent proximity between the crystallites in figure 2a is an artifact because of the projective nature of the TEM technique and sample thickness of about $200 \mathrm{~nm}$. When the cross section specimen is much thinner individual crystallites are evident as shown in figure $2 \mathrm{~b}$. The crystallites have a trapezoidal shape with flat planes on top forming an angle of $8^{\circ}$ with respect of the miscut substrate. This confirms that the growth of $\mathrm{ZnO}$ follows the c-axis of $4 \mathrm{H}-\mathrm{SiC}$. The nanocrystallites nucleate at the step edge and expand laterally and vertically, ultimately overgrowing the step, over the adjacent terraces, as shown by arrows in Figure $2 \mathrm{~b}$. The XTEM image also indicates the presence of a few monolayer-thick ZnO film on top of the $\mathrm{SiC}$ terraces in between the $\mathrm{ZnO}$ hexagons. The SEM images from the $\mathrm{ZnO}$-deposited samples also reveal $\sim 20 \mathrm{~nm}$ wide longitudinal stripes along the direction expected for the terraces of the miscut $\mathrm{SiC}$ substrate, however, with a stronger contrast (bright in Figures 1(a, b) than for the virgin substrate. A schematic representation is depicted in Figure 1c. The EDX and CL analyses presented below imply that there is a Stranski-Krastanov (3D-island on 2D-layer) growth mode for the $\mathrm{ZnO}$ on $\mathrm{SiC}$. Thus, the origin of the stripes is a decoration of $\mathrm{SiC}$ terraces by $\mathrm{ZnO}$. Indeed, a thin layer was observed by XTEM (Figure 2b).

Figure 3 shows a plan-view TEM image from an as-deposited sample after ion beam thinning from the substrate side. The image confirms the presence of the thin $\mathrm{ZnO}$ layer that completely covers the $\mathrm{SiC}$ terraces as seen by the Moirée pattern. In addition, Fig 3 reveals the 
presence of $\mathrm{ZnO}$ domains with a mean size of $40 \mathrm{~nm}$, which are slightly misoriented, exhibiting a mosaic structure. The misorientation of the grains is evident from the distortions of the Moiré pattern, which are denoted by arrows in Figure 3a. In our case the actual in-plane misorientation of the nanograins in respect to the $\mathrm{SiC}$ matrix is $0.3^{\circ}$. The mosaic structure of the film is also illustrated by the diffuse diffraction pattern in Figure 3b. In Figure 4, images obtained by mapping the elements $\mathrm{Zn}, \mathrm{O}$ and $\mathrm{Si}$, are presented along with the $\mathrm{SEM}$ image of the scanned area. The $\mathrm{Zn}$ and $\mathrm{O}$ signals are clearly correlated with the nano hexagons, but also with the stripes, however, of faint contrast consistent with the mosaic structure of the 2D-layer of $\mathrm{ZnO}$ not much thicker than a few atomic layers (about $1 \mathrm{~nm}$ ). The signal of $\mathrm{Si}$ was detected over the whole area of scanning which is due to a high penetration of the excitation electron beam, thus probing the SiC substrate. Nevertheless, the area where the $\mathrm{ZnO} \mathrm{HEX}$ nanorods are located, displayed a lower intensity of the Si signal.

In order to determine the epitaxial relationship of $\mathrm{ZnO}$ nanohexagons and $\mathrm{SiC}$ substrate we performed pole figure XRD measurements ( $\Phi$ scan). Pole figures are widely used to examine the epitaxial relationship or the in-plane orientation of $\mathrm{ZnO}$ films $[31,32]$. For the $\left\{\begin{array}{lll}1 & 12 \lambda\end{array}\right\}$ family of planes, sixfold peaks are expected, which reflects the hexagonal structure of the unit cell. Figure 5 shows the $\Phi$ scans of the $\mathrm{ZnO}$ hexagons $\left\{\begin{array}{llll}1 & 1 & \overline{2} & 2\end{array}\right\}$ family of planes together with the $\Phi$ scan of the $\left\{\begin{array}{llll}1 & 1 & 2 & 6\end{array}\right\}$ family of planes of the SiC substrate. The obvious six-fold symmetry unambiguously demonstrates that the $\mathrm{ZnO}$ hetero structures containing the hexagons are grown epitaxially. The XRD analysis ( $\theta-2 \theta$ pattern) of the $\mathrm{ZnO} / 4 \mathrm{H}-\mathrm{SiC}$ heterostructure exhibits only (0002) and (0004) diffraction peaks characteristic of $\mathrm{ZnO}$, which evidences a good structural quality. Table 1 presents data on interplanar space, lattice constant, strain and stress along c-axis obtained by Bragg's equation [33, 34] and biaxial strain model [35]. Using the interplanar spacing the stress along the c-axis of the $\mathrm{ZnO}$ film can be expressed as [36]: 


$$
\sigma_{f i l m}=\frac{2 c^{2}{ }_{13}-c_{33}\left(c_{11}-c_{12}\right)}{2 c_{13}}\left(\frac{c_{f i l m}-c_{b u l k}}{c_{\text {bulk }}}\right)
$$

where $c_{\text {film }}$ and $c_{b u l k}$ are the c-lattice parameters of the $\mathrm{ZnO}$ thin film and bulk reference, respectively. The values of the elastic constant of single-crystal $\mathrm{ZnO}$ are used, $c_{11}=208.8 \mathrm{GPa}$, $c_{33}=213.8 \mathrm{GPa}, c_{12}=119.7 \mathrm{GPa}$ and $c_{13}=104.2 \mathrm{GPa} . c_{B u l k}=5.2067 \AA$ as obtained from the ASTM card for bulk $\mathrm{ZnO}$ [33-36]. From Table 1 one can conclude that the $\mathrm{ZnO} / 4 \mathrm{H}-\mathrm{SiC}$ heterostructures are virtually unstrained, i.e. the $\mathrm{ZnO}$ nanohexagons are relaxed. From the TEM study it also follows that the nanohexagons are in perfect epitaxial relation with the substrate having the $[0001]_{\mathrm{ZnO}} / /[0001]_{4 \mathrm{H}-\mathrm{SiC}}$ and the $[1010]_{\mathrm{ZnO}} / /[1010]_{4 \mathrm{H}-\mathrm{SiC}}$ as shown in the selected area diffraction (SAD) in figure 6(a), which was taken from a typical crystallite. In the rare case of coalescence of the nanohexagons, threading dislocations are observed in the resultant larger hexagon, as shown by an arrow in figure 6(b). Figure 6 (c) is a high-resolution micrograph from the $\mathrm{ZnO} / 4 \mathrm{H}-\mathrm{SiC}$ interface. The crystal planes are continuous across the heterointerface to the $\mathrm{ZnO}$ layer on the $\mathrm{SiC}$ terraces as well as to the hexagons confirming the epitaxial quality of the film. Growth of faceted $\mathrm{ZnO}$ nanorods on $\mathrm{n}$-type $4 \mathrm{H}-\mathrm{SiC}$ by using metal catalyst is reported in Ref. [38]. However, the emission spectra of the prepared material possess strong luminescence in the visible range, typically assigned to defects. We investigated the luminescence properties of the fabricated $\mathrm{ZnO}$ nanohexagons containing samples by cathodoluminescence measurements at room temperature in terms of possible optoelectronic applications. The CL spectra of the sample demonstrated intense peak of ultraviolet emission at $\lambda=376 \mathrm{~nm}$ while the visible luminescence was negligible (Figure 7a). The spectral line of the UV emission is very narrow - the full width at half maximum is as low as $12 \mathrm{~nm}$. We assign the luminescence observed to the near band edge (NBE) excitonic emission [10]. Moreover, probing over the sample surface with different concentration of $\mathrm{ZnO}$ nanohexagons displayed different signal intensity, but the characteristic 
features of the spectra did not change. In order to differentiate the contribution of the emission from nanohexagons and the $\mathrm{ZnO}$ stripes, we recorded their emission spectra separately. In Figure $7 \mathrm{CL}$ spectra along with the probed regions are shown. Figure 7 (b) represents the panchromatic image of the sample. Light is emitted by the whole area covered by $\mathrm{ZnO}$, i.e. CL signal is also observed from the stripes around hexagons, proving their emitting ability and $\mathrm{ZnO}$ nature. However, it is evident that the emission intensity from $\mathrm{ZnO}$ stripes on top of the $\mathrm{SiC}$ terraces is significantly lower than that from $\mathrm{ZnO}$ hexagons.

The spectra from both areas display the only peak of NBE emission. The absence of visible emission which is related to point defects in the material suggests a good stoichiometry of both types of $\mathrm{ZnO}$. At the same time, the difference in the emission intensities may be explained by a difference in the concentrations of extended structural defects. It has been reported that structural defects as dislocations are mainly responsible for quenching of the luminescence intensity [23]. The epitaxial interface followed by high structural quality, is a prerequisite of obtaining the high light emission efficiency. Since the $\mathrm{ZnO}$ nanorods are relaxed heteroepitaxial structures, misfit dislocations are expected, although they are invisible in the TEM images. We assume that they do not affect the CL properties since they are confined at the interface.

\section{Conclusions}

The fabrication feasibility of high-quality $\mathrm{ZnO}$ nano-crystal material by heteroepitaxial growth on p-type $4 \mathrm{H}-\mathrm{SiC}$ has been demonstrated. The $\mathrm{ZnO}$ nanohexagons form via StranskiKrastanow growth mode: a few monolayers of $\mathrm{ZnO}$ grow on the $\mathrm{SiC}$ terraces on top of which $\mathrm{ZnO}$ nanohexagons evolve. The hexagons are regular in shape with a- and c-plane faceting. A perfect epitaxial relationship and a high quality interface between the $\mathrm{ZnO} \mathrm{HEX}$ and the $\mathrm{SiC}$ substrate was observed. The high intensity monochromatic emission demonstrated in the $\mathrm{ZnO}$ nanohexagons is attributed to the single crystal structure, epitaxial relation and high quality 
heterointerface. Accounting for the high optical quality and the availability of $p-n$ junctions, the structures prepared in this study can be considered as a promising key element for nanooptoelectronics.

\section{Acknowledgments}

The financial support from the Swedish Institute, Swedish Research Council and the VINNEX Centre FunMat is greatly acknowledged. The authors are grateful to Prof. J. Stoemenos for TEM images and fruitful discussions. 


\section{References}

[1] Ü. Özgür, Ya.I. Alivov, C. Liu, A. Teke, M. Reshchikov, S. Doğan, V. Avrutin, S.-J. Cho and H. Morkoç, J. Appl. Phys. 98 (2005) 041301

[2] M. H. Huang, S. Mao, H. Feick, H.Yan, Y. Wu, H. Kind, E. Weber, R. Russo and P. Yang, Science 292 (2001) 1897

[3] S. Cha, J. Yang. Y. Choi, G. A. Amaratunga, G. W. Ho, M. E. Welland, D. G. Hasko, D.J. Kang and J. M. Kim, Appl. Phys. Lett. 89 (2006) 263102

[4] M. Law, L. E. Greene, J. C. Johnson, R. Saykally and P. D. Yang, Nat. Mater. 4 (2005) 455

[5] Z. L. Wang and J. Song, Science 312 (2007) 242

[6] Y. Quin, X. Wang, L. Z. Wang, Nature 451 (2008) 809

[7] K. Vanheusden C. H. Seager, W. L. Warren, D. R. Tallant, J. A. Voigt, Appl. Phys. Lett. 68 (1996) 403

[8] F. Leiter, H. Zhou, F. Henecker, A. Hofstaetter, D. M. Hoffman, B. K. Meyer, Physica B 908 (2001) 308

[9] D.C. Look, J. W. Hemsky, and J. R. Sizelove, Phys. Rev. Lett. 82 (1999) 2552

[10] V. Khranovskyy, G. R. Yazdi, G. Lashkarev, A. Ulyashin and R. Yakimova, Phys. Stat. Sol. A 205 (2008) 144

[11] M. Joseph, H. Tabata and T. Kawai, Jpn. J. Appl. Phys. 38 (1999) 1205

[12] K. Minegishi, Y. Koiwai, Y. Kikuchi, K. Yano, M. Kasuga and A. Shimizu, Jpn. J. Appl. Phys 36 (1997) L1453

[13] K. K. Kim, H.-S. Kim, D.-K. Hwang, J.-H. Lim, and S.-J. Park, Appl. Phys. Lett. 83 (2003) 63

[14] D. C. Look, D. C. Reynolds, C. W. Litton, R. L. Jones, D. B. Eason, and G. Cantwell, Appl. Phys. Lett. 81 (2002) 1830

[15] Y. R. Ryu, T. S. Lee, J. H. Leem, and H. W. White, Appl. Phys. Lett. 83 (2003) 4032

[16] X.-L. Guo, J.-H. Choi, H. Tabata and T. Kawai, Jpn. J. Appl. Phys. 40 (2001) L177

[17] T. Aoki, Y. Hatanaka and D. C. Look, Appl. Phys. Lett. 76 (2000) 3257

[18] G. T. Du, W. F. LiU, J. M. Bian, L. Z. Hu, H. W. Liang, X. S. Wang, A. M. Liu and T. P. Yang, Appl. Phys. Lett. 89 (2006) 052113

[19] A. Ashrafi, B. Zhang, N. Binh, K. Wakatsuki and Y. Segawa, Jpn. J. Appl. Phys. 43 (2004) 1114

[20] A. Ashrafi, N. Binh, B. Zhang, Y. Segawa, Appl. Phys. Lett. 84 (2004) 2814 
[21] S. Hong, H. Ko, Y. Chen, T. Yao, J. Crystal Growth 209 (2000) 537

[22] W. I. Park and G.-C. Yi, Adv. Mater. (Weinheim, Ger.) 16 (2004) 87

[23] A. B. Djurisic and Y. H. Leung, Small 2 (2006) 944

[24] S.-H. Park, S.-Y. Seo, S.-H. Kim, and S.-W. Han, Appl. Phys. Lett. 88 (2006) 251903

[25] J. Y, Y. Ryu and K. Yong, Nanotechnology 16 (2005) 1712

[26] V. Khranovskyy, G. R. Yazdi, A. Larson, S. Hussain, P-O. Holtz, R. Yakimova, J. Opt. Adv. Mater. 10 (2008) 2629

[27] M. Syväjärvi, R. Yakimova, H. Jacobsson and E. Janzén, J. Appl. Phys. 88 (2000) 1407

[28] M Syväjärvi, R Yakimova, A-L. Hylen and E Janzén, J. Phys.: Condensed Metter 11 (1999) 10019

[29] A. Shuchukin and D. Bimberg, Rev. Mod. Phys. 4 (1999) 71

[30] H. Nakagawa, S. Tanaka, and I. Suemune, Phys. Rev. Lett. 91 (2003) 226107-1

[31] C. Gorla, N. Emanetoglu, S. Liang, W. Mayo, Y. Lu, M. Wraback and H. Shen, J. Appl. Phys. 85 (1999) 2595

[32] B. Zhang, L. Manh, K. Wakatsuki, T. Ohnishi, M. Lippmaa, N. Usami, M. Kawasaki and Y. Segawa, Jap. J. Appl. Phys. 42 (2003) 2291

[33] B. Zhu, X. Sun, S. Guo, X. Zhao, J. Wu, R. Wu and J. Liu, J. Journ. Appl. Phys 45 (2006) 7860

[34] J. Hinze. and K. Ellmera, J. Appl. Phys. 88 (2000) 2443

[35] I. Akyuz, S. Kose, F. Atay and V. Bilgin, Semicond. Sci. Technol. 21 (2006) 1620

[36] H. Hsu, C. Cheng, C. Chang, S. Yang, S.-C. Chang and W.-F. Hsieh, Nanotechnology 16 (2005) 297

[37] Powder Diffraction File, Joint Committee on Powder Diffraction Standards, ICDD, Newtown Square, PA, 2001, Card 36-1451

[38] Q. X. Zhao, P. Klason, M. Willander, Appl. Phys. A 88 (2007) 27 


\section{List of figures:}

Fig. 1. SEM images of $\mathrm{ZnO} H E X$ nanostructures on a stepped $\mathrm{SiC}$ surface (a) an overview, (b) a closer view: the light regions are $\mathrm{ZnO}$, the dark area between the stripes reflects the steps; (c) schematic representation of $\mathrm{ZnO}$ growth on $4 \mathrm{H}-\mathrm{SiC}$ vicinal surface. The shadowed areas indicate $\mathrm{ZnO}$ film on the $\mathrm{SiC}$ terraces, corresponding to the bright area in Figure $1 \mathrm{~b}$.

Fig. 2. $\mathrm{XTEM}$ images of the $\mathrm{ZnO} / \mathrm{SiC}$ structure. (a) overview, b) $\mathrm{ZnO}$ nano rods and a thin $\mathrm{ZnO}$ layer covering the $\mathrm{SiC}$ substrate (indicated by arrows) between the nano rods.

Fig. 3. a) Plan view TEM and b) corresponding selected area electron diffraction pattern from an area of the sample containing thin $\mathrm{ZnO}$ layer covering the $\mathrm{SiC}$ substrate (apparent from Moirée fringes).

Fig. 4. SEM image and corresponding EDX elemental maps of Si, Zn and O from a sample with $\mathrm{ZnO}$ deposited on a $\mathrm{SiC}$ substrate.

Fig. 5. $\Phi$ scans of the $\left\{\begin{array}{llll}1 & 1 & 2 & 2\end{array}\right\}$ family of planes of the $\mathrm{ZnO} / 4 \mathrm{H}-\mathrm{SiC}$ heterostructure and with the $\Phi$ scans of the $\left\{\begin{array}{llll}1 & 1 & 2 & 6\end{array}\right\}$ family of planes of the $8^{\circ}$ off-cut $4 \mathrm{H}-\mathrm{SiC}$ substrate.

Fig. 6. XTEM images from the $\mathrm{ZnO} / \mathrm{SiC}$ heterointerface: (a) selected area diffraction (SAD), taken from a $\mathrm{ZnO}$ crystallite; (b) demonstration of threading dislocation (marked by arrow); (c) high-resolution (HREM) image of the interface between a $\mathrm{ZnO}$ nano hexagon and the $4 \mathrm{H}-\mathrm{SiC}$ substrate; respective interplanar distances are indicated. 
Fig. 7. (a) RT CL spectra taken from $\mathrm{ZnO}$ grown on p-4H-SiC . The corresponding regions are marked on the panchromatic CL image (b). The spectral range, where a possible defect emission (DE) could be observed is indicated. 


\section{Table captions:}

Table 1. The XRD data of different ZnO samples: $2 \theta_{(002)}-(002)$ peak position; $\mathrm{d}$ - interplanar space, $\mathrm{c}$ - c-lattice constant; $\varepsilon$ - strain; $\sigma$ - stress. 
Table 1.

\begin{tabular}{|ccccccc|}
\hline Sample & $2 \theta_{(002)}{ }^{\circ}$ & $\mathrm{d}, \AA$ & $\mathrm{c}, \AA$ & $\varepsilon, 10^{-3}$ & $\sigma, \mathrm{GPa}$ & Reference \\
\hline ZnO nano & 34.43 & 2.6033 & 5.2066 & -0.08 & +0.002 & This work \\
hexagons & & & & & & \\
ZnO films & 34.51 & 2.5975 & 5.1950 & -2.24 & +0.5195 & {$[26]$} \\
ZnO powder & 34.42 & 2.6035 & 5.207 & - & - & {$[37]$} \\
\hline
\end{tabular}




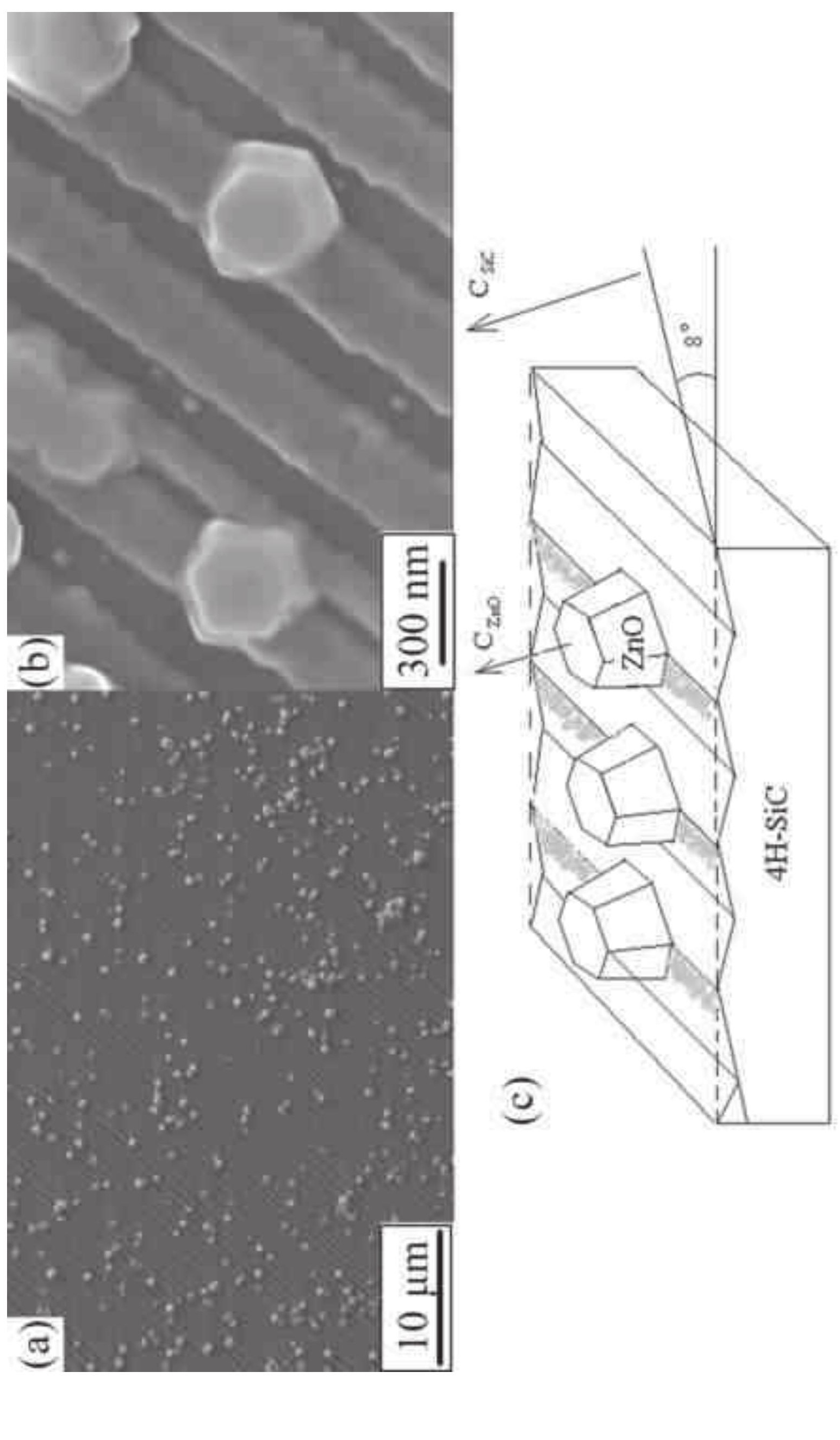




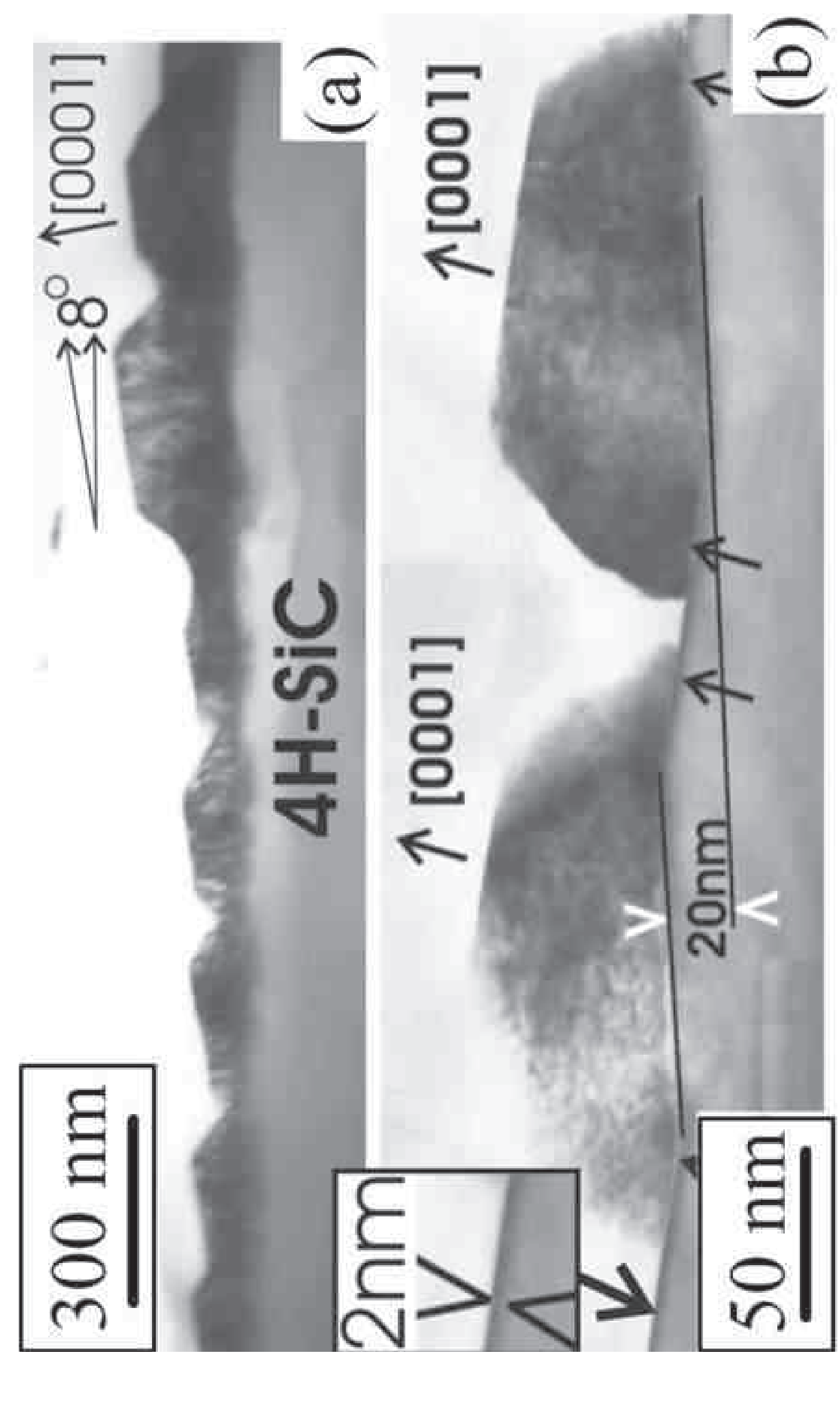




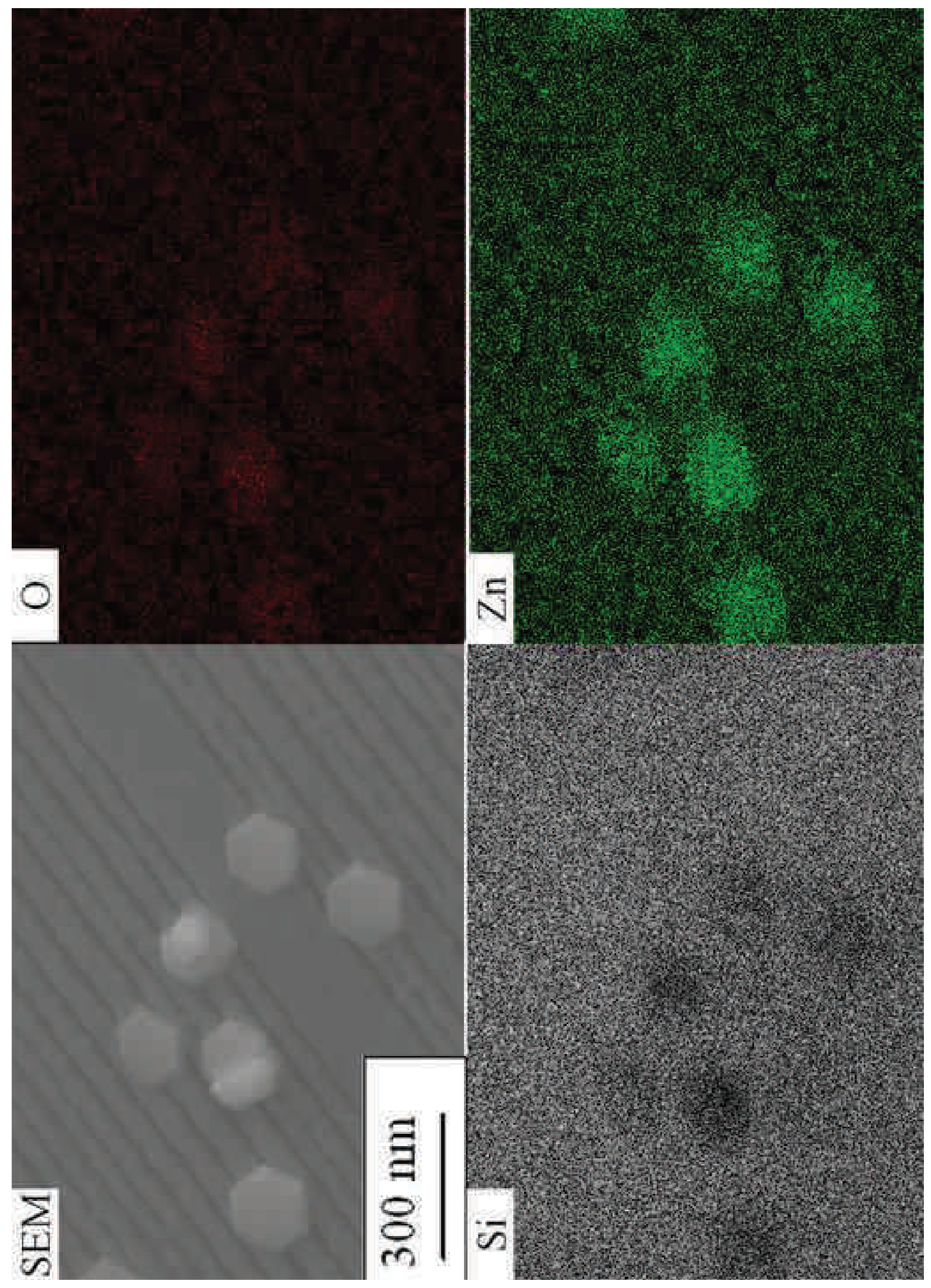




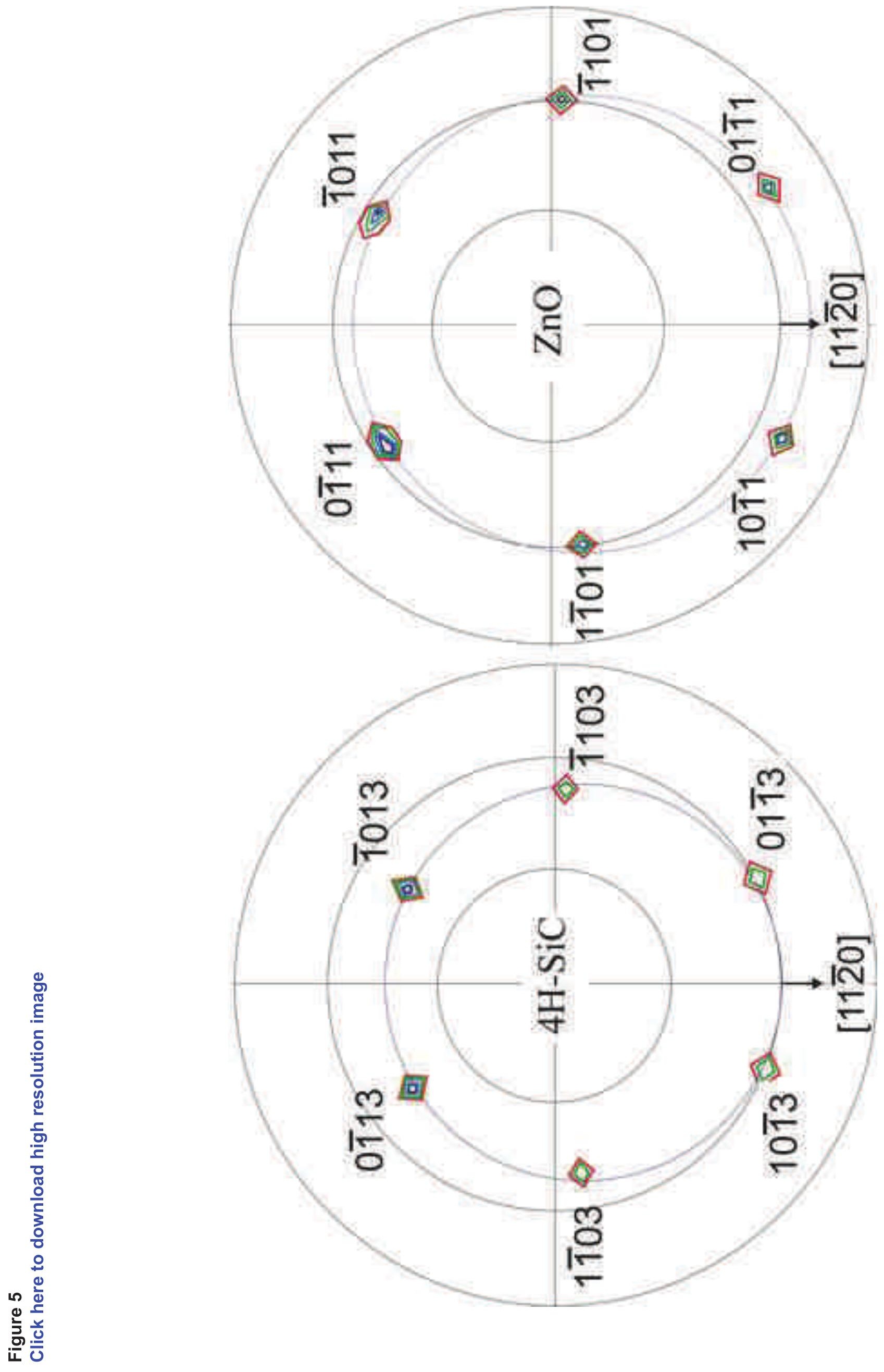


Click here to download high resolution image
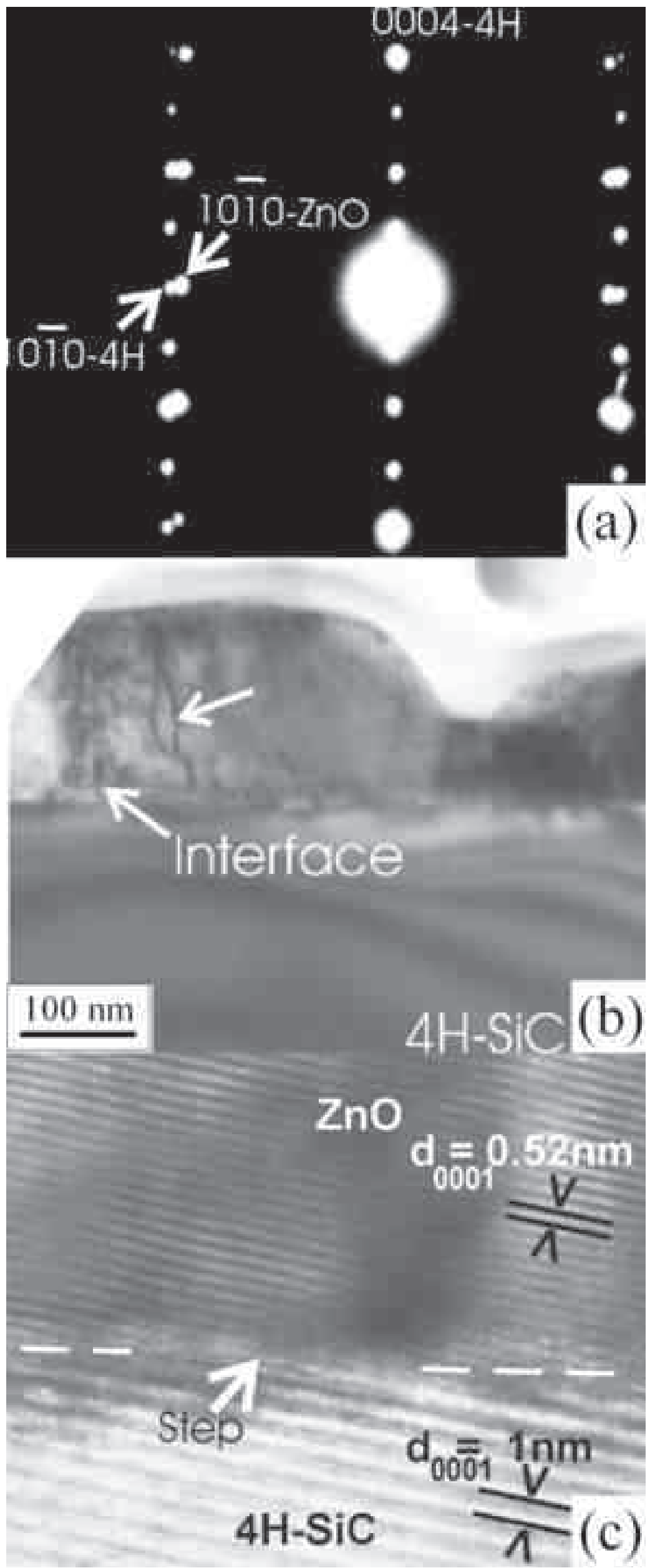


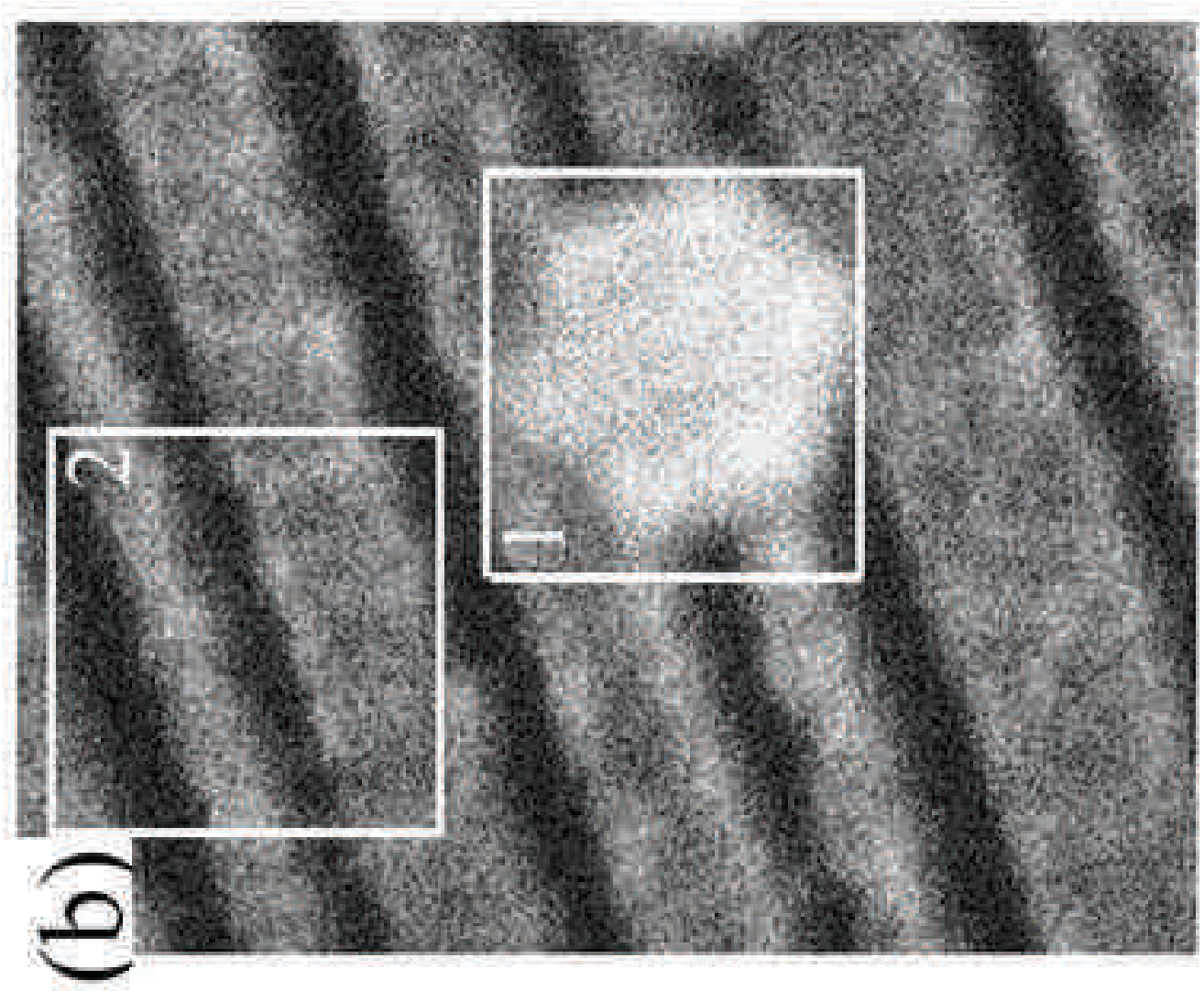

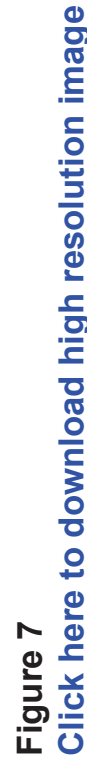

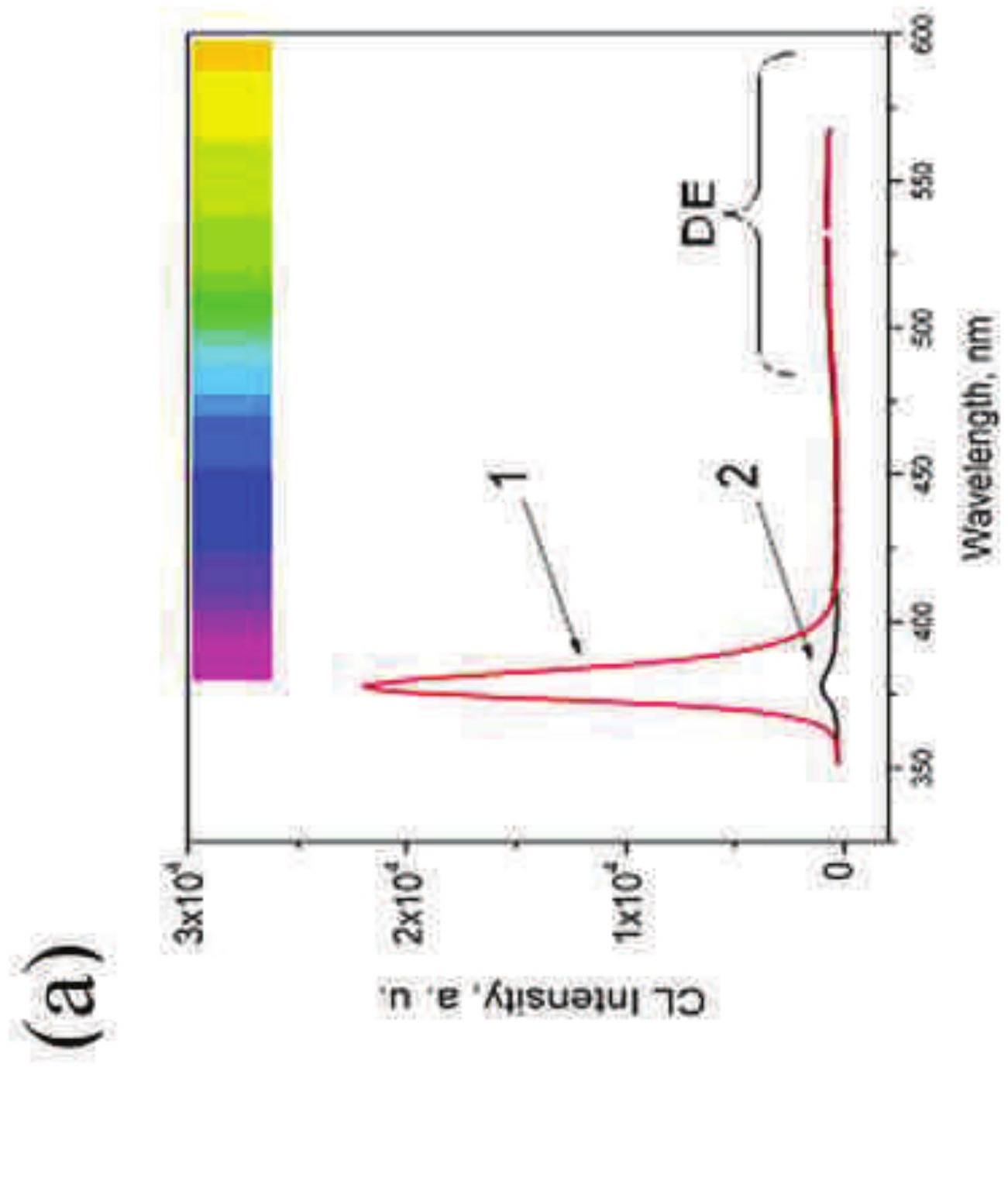

